\title{
Analysis on Climate Change Trend in Guangzhou Area in Recent 65 Years
}

\author{
Wenzheng $\mathrm{Yu}^{1}$, Haitao Liu ${ }^{1}$ and Jin Wang ${ }^{2}$ \\ ${ }^{1}$ College of Environmental Science and Engineering, Nanjing University of \\ Information Science \& Technology, Jiangsu Nanjing, China \\ ${ }^{2}$ College of Information Engineering, Yangzhou University, Yangzhou, China
}

\begin{abstract}
Based on the climate data and the social statistics of Guangzhou observatory from 1952 to 2014, this paper used Linear trend analysis, Morlet wavelet transformanahysts, Mann-Kendall mutation test etc, to analyze the trend of climate change in-Guangzhou nearly 65 years. The results showed that climatic conditions in Guangzhou in recent 65 years showed a warming and drying trend and this trend had become increasingly apparent since the 1990s. The average temperature increased at the rate of $0.153^{\circ} \mathrm{C} / 10 \mathrm{a}$ , at the same time, the warming rate of average minimum temperature was higher than the average maximum temperature $\left(0.15^{\circ} \mathrm{C} / 10 \mathrm{a}>0.14 \mathrm{C} / 10 \mathrm{a}\right)$. The annual precipitation had a slight increase at the rate of $37.77 \mathrm{~mm} / 10 \mathrm{a}$. Under the effect of urban dry-island, the average relative humidity had a decreasing trend at the rate of $0.94 \% / 10 a$ and the sunshine hours showed a decreasing trend with fluctuation.
\end{abstract}

Keywords: Climate change, Trend, Gwangzhou Morlet wavelet transform

\section{Introduction}

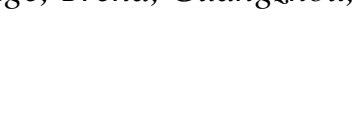

In recent decades, as the increasing rend of global warming and sea-level rise, the phenomenon of extreme weather has occurred frequently, people have to face the important problem of climate issues under the development of human society. Urban has become the maingathering area for human-beings and it is the center for different kind of human-actiyities. In the process of the rapid development of the city, the trend and rules to the urban climate chânge have gained increasing attention by the relevant experts and scholars. Using the IMAG 2.0 simulation, Alcamo J, etc assessed the global communitythe biosphere-the climate system and analyzed the subsystem which is perform calculation for the year 2100, the results showed that "Urban heat island effect" and "Urban climate effect" were inevitable for the development of a big city [1]. Hughes, etc found that utban development in South Africa led to the city warming, while there was no changes in rural. Based on the precipitation data of the western United States and the Arab and regions in the recently 108 years [2], Shepherd found that with the development of urbanization, the average rainfall had increased 12\% 14\% [3]. After analyzing the climate change in Xining, Zhang, etc found that the strength of Xining "Dry island effect" had intensified with the development of urbanization [4]. Shaw Chen Liu, etc analyzed the change of sunshine hours in Taiwan, he found that from the beginning of the 1960s, sunshine hours in Taiwan had decreased rapidly and this phenomenon is also evident in Shanghai [5]. Wang Yan Jiao, etc used the surface temperature data of TERRA/MODIS remote sensing inversion model, combining with changes of NDVI and surface albedo at the same period, he found that Urban island effect had an increasing trend with the development of urbanization in Beijing, while the Urban island effect was more significant in summer [6]. 
Guangzhou is located in south China in the range of longitude $112^{\circ} 57^{\prime} \sim 114^{\circ} 03^{\prime}$ and latitude $22^{\circ} 26^{\prime} \sim 23^{\circ} 56^{\prime}$. It is in the subtropical coastal and it has maritime subtropical monsoon climate. The climate of Guangzhou is warm and rainy, it has adequate light and heat, it also has long summer days short frosty days. The year leading wind direction of Guangzhou is southeast by east, this area has been affected by tropical cyclones. In the nearly 65 years, the study of the trend and rule of climate change in Guangzhou has been gradually drawn wide attention by the government and relevant scholars.

In this study we use the observational data from Guangzhou weather stations from 1952 to 2014. The climatic factors we selected are the annual average temperature, the average minimum temperature, the average maximum temperature, the annual precipitation, the average relative humidity and the sunshine hours. The main research methods are linear trend analysis, wavelet analysis and Mann-Kendall mutation inspection. This paper aims to analysis the climate indicators in nearly 65 years in Guangzhou and found the law of the climate change, which were better to analyze its relationship with the urbanization of Guangzhou and guidance for development of this city in future.

\section{Climate Change Trends}

The article selects the annual average temperature (compared with the average maximum temperature and the average minimum temperature) the precipitation, the average relative humidity and the sunshine hours from 1952-2014 in Guangzhou to analysis the law and situation of climate change.

\subsection{Characteristics of Temperature Change}

\subsubsection{Analysis on the Average Temperature Change}

The average temperature change in Guangthou in nearly 65 years is shown in Figure 1, it exhibit volatility on the rise overall and the warming rate are $0.153{ }^{\circ} \mathrm{C} / 10$. It adopted a confidence level of $95 \%$ of the significant test(trend factor $\mathrm{R}=0.296>$ threshold $\mathrm{r}_{0.01}=$ 0.24415). The minimtm number of the average temperature is $21.3^{\circ} \mathrm{C}$ which appeared in 1976 and 1984. By contrast. the maximum number is $23.2^{\circ} \mathrm{C}$ which appeared in 2006 and 2007. The range of them is $1.9^{\circ} \mathrm{C}$ In addition, Figure 1 shows that the warming trend of the annual average temperature in Guangzhou are intensified from 1970s to 1980s, and has a cooling trend in the beginning of this century. However, the specific observations in recent decades show that the lowest average temperature number just appeared on the 1970 s to 1980 s, while the highest temperature occurs in the beginning of this century, which explained that the fluctuations of Guangzhou's temperature are consistent with the rate of the global climate warming in nearly several decades.

\subsubsection{Analysis on the Average Maximum and Minimum Temperature Change}

As shown in Figure 1, the trend of the average maximum temperature and the average minimum temperature are consistent with the average temperature which are fluctuant and increasing. In addition, As shown in Table 1 and Figure 1, The warming rate of the average maximum temperature and the average minimum temperature is lower than the annual average temperature $\left(0.153{ }^{\circ} \mathrm{C} / 10\right)$, which are $0.140{ }^{\circ} \mathrm{C} / 10 \mathrm{a}$ and $0.150{ }^{\circ} \mathrm{C} / 10 \mathrm{a}$ respectively, and both of them have passed the confidence level of $90 \%$ significance test (The trend coefficient of the average maximum temperature $\mathrm{R}=0.211>$ threshold $\mathrm{r}_{0.1}=$ 0.2058 , the trend coefficient of the average minimum temperature $\mathrm{R}=0.234>$ threshold $\left.r_{0.1}=0.2058\right)$. Thirdly, As shown in the analysis of Figure 1, The range of the average maximum and minimum temperatures are $2.4{ }^{\circ} \mathrm{C}$ and $2.3{ }^{\circ} \mathrm{C}$, which show the increasing high probability of the extreme temperatures weather events in Guangzhou. At the same 
time, the probability of the extreme temperatures weather events increased significantly from modern times.

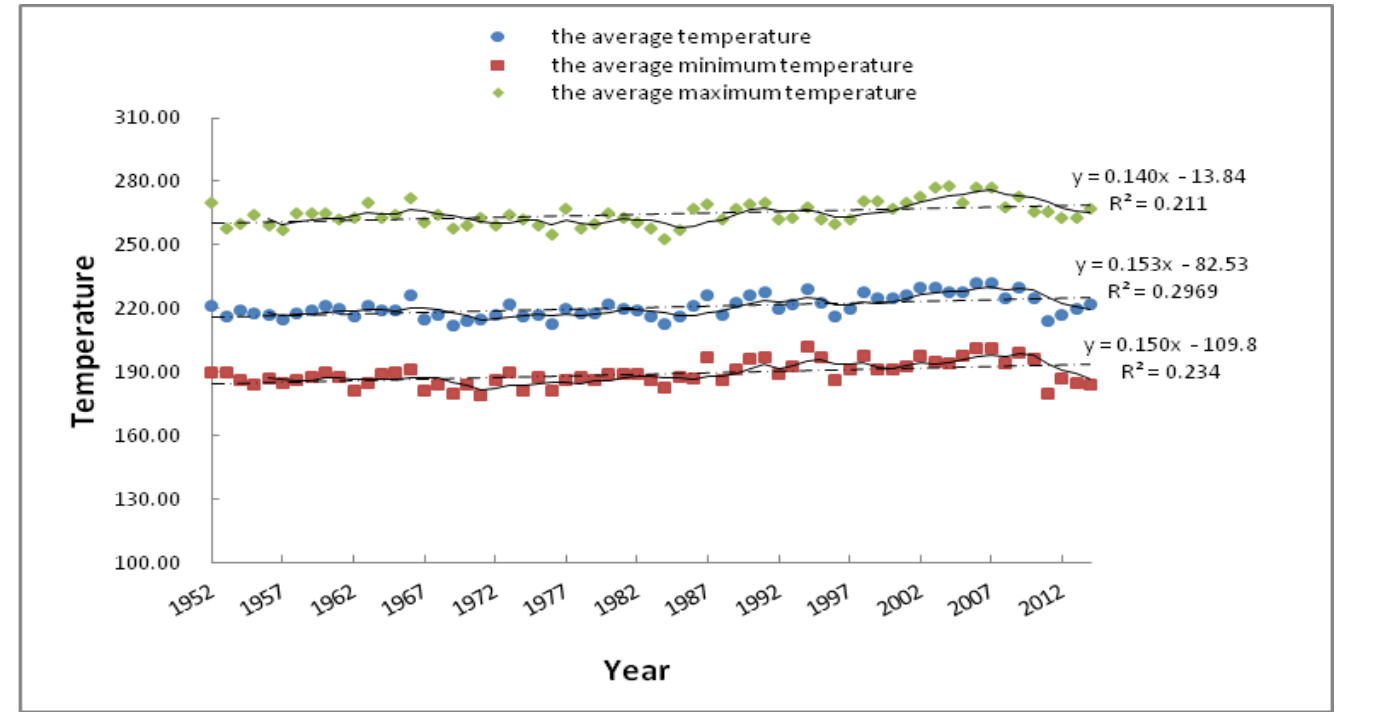

Figure 1. Change Characteristics of Temperature

Note: The dashed line is the linear trend line; the solid line is the five-year moving average.

\subsection{Analysis on Variation Characteristic of the Precipitation}

As shown in Figure 2, The precipifation in Guangzhou has a slight upward trend with the rate of $37.77 \mathrm{~mm} / 10 \mathrm{a}$ in nearly 65 years, and it has frequent fluctuations. It's significance has passed the $90 \%$ signlficance cest (trend coefficient $\mathrm{R}=0.025<$ threshold $\left.r_{0.1}=0.2058\right)$. The range of precipitation is $1520.9 \mathrm{~mm}$.

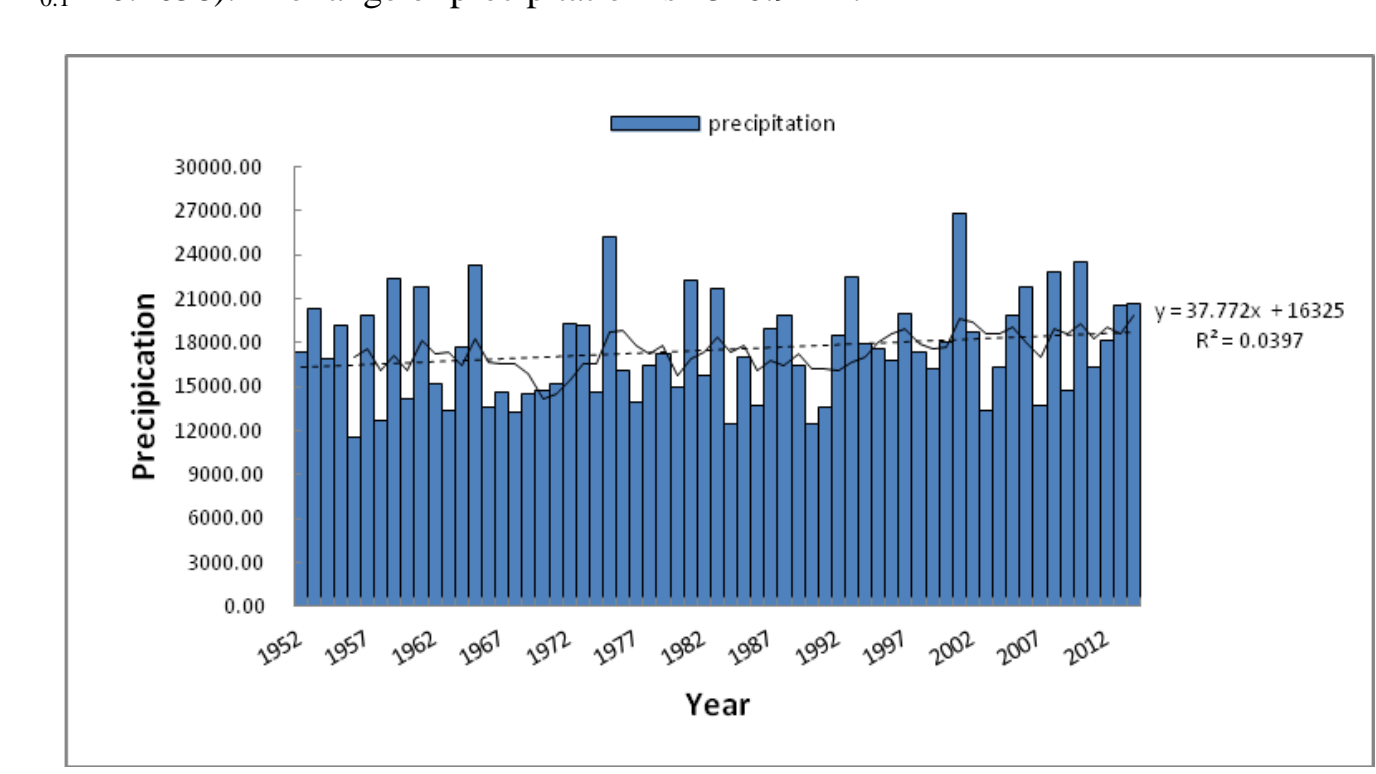

Figure 2. Change Characteristics of Precipitation

Note: The dashed line is the linear trend line; the solid line is the five-year moving average. 


\subsection{Analysis on the Average Relative Humidity Characteristics}

As shown in Figure 3, the average relative humidity in Guangzhou generally has a decreasing trend at the rate of $0.94 \% / 10 \mathrm{a}$ in nearly 65 years. And it has passed the confidence level of $95 \%$ significance test (trend coefficient $\mathrm{R}=0.302>$ Threshold $\mathrm{r}_{0.05}=$ 0.244 ). In addition, the average relative humidity shows a significant decreasing and increasing trend in volatility of the decade.

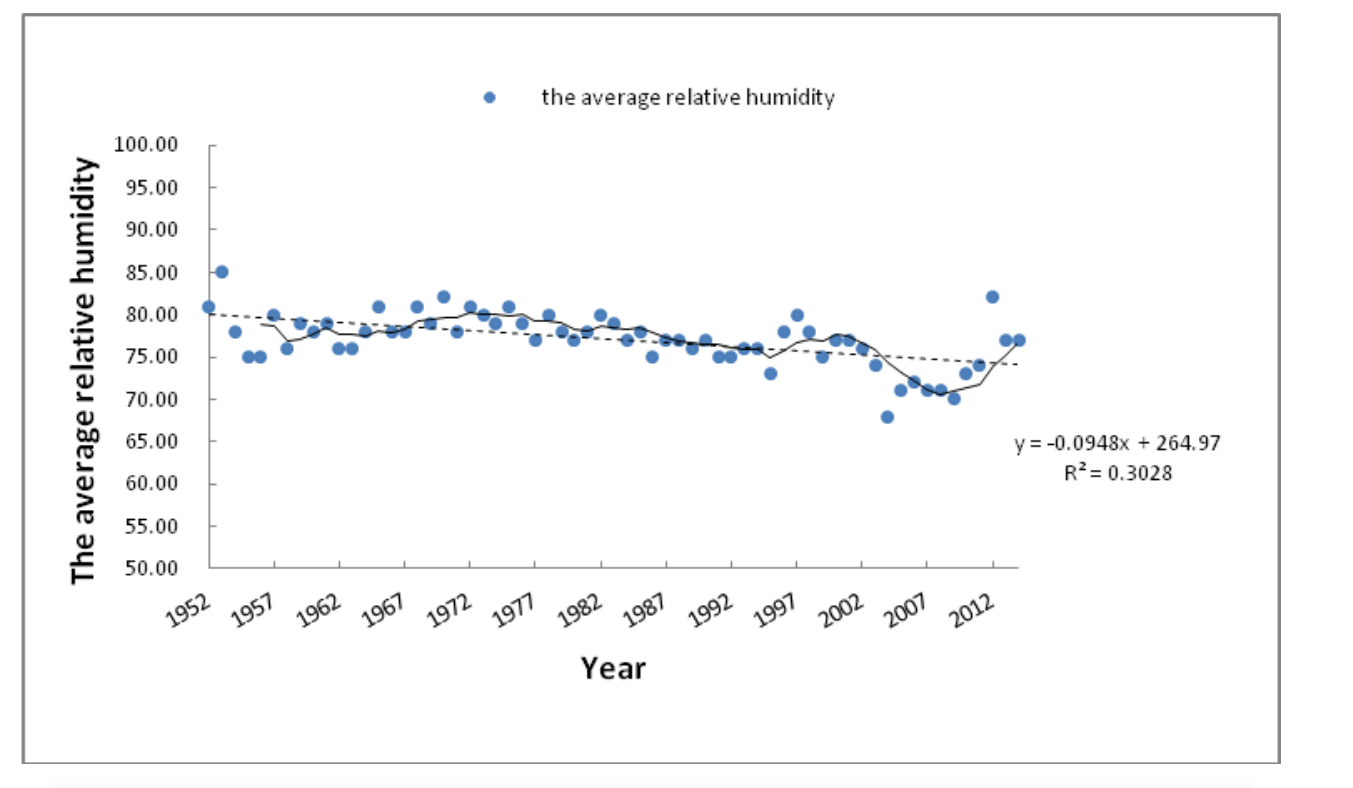

Figure 3. Change Characteristics of the Average Relative Humidity

Note: The dashed line is the linear trend line thy solid line is the five-year moving average.

\subsection{Analysis on the Characteristics of the Sunshine Hours Change}

As shown in Fiĝure 4, the sunshine hour in Guangzhou shows a decreasing trend in volatility, and the rate is $88.6 \mathrm{~h} \times 10 \mathrm{a}$. And it has passed the $99 \%$ confidence level of significance tesi (trend coefficient $\mathrm{R}=0.488>$ Threshold $\mathrm{r}_{0.01}=0.317$ ). The average sunshine hours in Guangzhou City is $1720.9 \mathrm{~h}$, the maximum number is $2228.2 \mathrm{~h}$ in 1963 , while the mmmum number is $1209.8 \mathrm{~h}$ in 1997 . The range of the sunshine hours is 1018.4h which is a wide gap. 


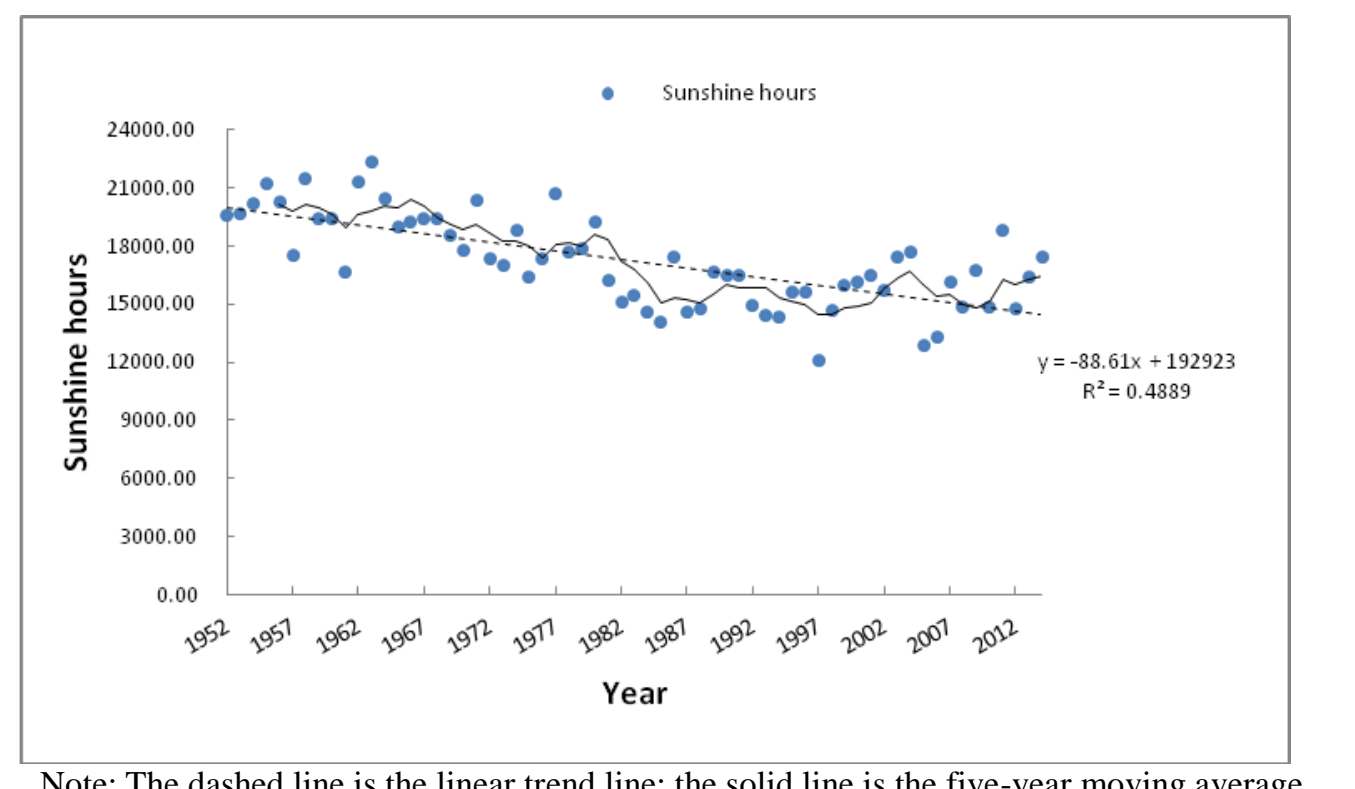

Note: The dashed line is the linear trend line; the solid line is the five-year moving average.

Figure 4. Change Characteristics of the Sunshine Percentage

\subsection{Summary}

We can seen from the above analysis that Guangzhou's climate change shows a warming trend in nearly 65 years overall. The annual average temperature, the annual average maximum temperature and the annual average minimum temperature exhibit different degrees of increase. The preeipitation is als showing a growth trend, but the average relative humidity and the sunshine hours are showing a significant downward trend. The reasons and the driving factors of these changes need further study and analysis.

\section{Analysis on the Characteristics of Cyclic Variation in Climate}

Figure 5 is the power spectrum diagram of the main meteorological factors in Guangzhou during the nearly 65 years after Morlet wavelet transform. The picture shows that the greater the wavelet power, the more densely for the contour line. Some of them are surrounded by the thick broken line is indicated that has pass through the measure cycle test of Gaussian noise test in red scale periodic at significance level of 0.05 ; inverted-cone * line consider as the cone of influence, it encircles the measure cycle of which by partially removing the scale boundary effect, while the rest of the power spectrum under the influence of wavelet edge effects, and there having greater uncertainty for cycle thâracteristics.

\subsection{Amalysis on the Variations of the Temperature Cycling}

The average variations of temperature cycle as shown in Figure 5 (a), among time series, there exists observably quasi-3a, quasi-periodic scale $3 \sim 4 \mathrm{a}$ and quasi-4a in measure cycle. The intensity of these cycles variation with time, have all passed the test of significance 0.05 . Quasi 3a spectral cycle characteristics mainly appear in the year of 1963 - 1971, the average annual temperature showed in a downward trend; quasi $3 \sim 4 \mathrm{a}$ spectral cycle characteristics mainly appear in the period between 2005 to 2013, the average temperature in the period experienced the variation from rising to declining. Quasi 4a spectral cycle characteristics mainly appear in the period from 1984 to 2002, and it keeps the rising trend in this period. Wavelet power spectrum analysis also detected quasi-periodic and quasi- $6 \sim 8$ a above $8 \sim 12 \mathrm{a}$ intergenerational cycle scale, but did not pass the 0.05 level of significance test. 


\subsection{Analysis on the Variations of the Precipitation Cycling}

The average variations of precipitation cycle as shown in Figure 5 (a), among time series, there exists observably quasi $2 \sim 5 \mathrm{a}, 2 \sim 4 \mathrm{a}$, quasi-periodic scale $2 \sim 7 \mathrm{a}$ and quasi $3 \mathrm{a}$ in measure cycle. Quasi $2 \sim 5 \mathrm{a}$ spectral cycle characteristics mainly appear in the year of 1952-1970, there showed an increasing trend for the precipitation variation during this period. The quasi $2 \sim 4$ a cycle characteristics mainly appear in the period between 1970 to 1989, the precipitation in the period experienced the variation from rising to declining; quasi $2 \sim 7$ a periodic characteristics mainly appear in the period from 1982 to 2013, because of the long time span, there appeared bigger fluctuation for precipitation. Periodic features quasi 3a distributed in 2003 to 2006, and it keeps the rising trend in this period. The rest of the year cycle was not significant by $95 \%$ of the test.

\subsection{Analysis on the Variation of the Average Relative Humidity Cycling}

The average variations of cycle of mean relative humidity as shown in Figure 5 (c), among time series, there exists observably $3 \mathrm{a}$ and quasi $3 \mathrm{a}$ and $4 \sim 6 \mathrm{a}$ quasi-beriodic features. 3a quasi-periodic characteristics occurred mainly during 1967 to 1972 , there are all showed fluctuations in cycling for average relative humidity during this period, the quasi $4 \sim 6$ a period characterized mainly occurred in the period from 1994 to 2010, during that period the average relative humidity experienced the variation from declining to rising declining. Detected remaining 4a, $3 \sim 5$ a and $5 \sim 7$ a have not passed the 0.05 level of significance test.

\subsection{Analysis on the Variations of the Surshine Hours Duration Cycling}

The average variations of the sunshine hours duration cycle as shown in Figure 5 (d), among time series, there exists observably quasi-3a, 4a quasi-periodic and quasi-scale 3 4a in measure cycle, meanwhile the intensity of these cycles variation with time. Periodic features quasi 3a appears in 1970 to 1986 , the sunshine duration experienced the cycling variation from declining to rising. 4a guasi-periodic feature mainly occurred during 1957 to 1965 , during that period the number ot hours of sunshine showing the variation trend from declining to rising. Quasi $3 \sim 4$ a period characterized mainly in the 2000-2013, the sunshine duration experienced the cycling variation from rising to declining.
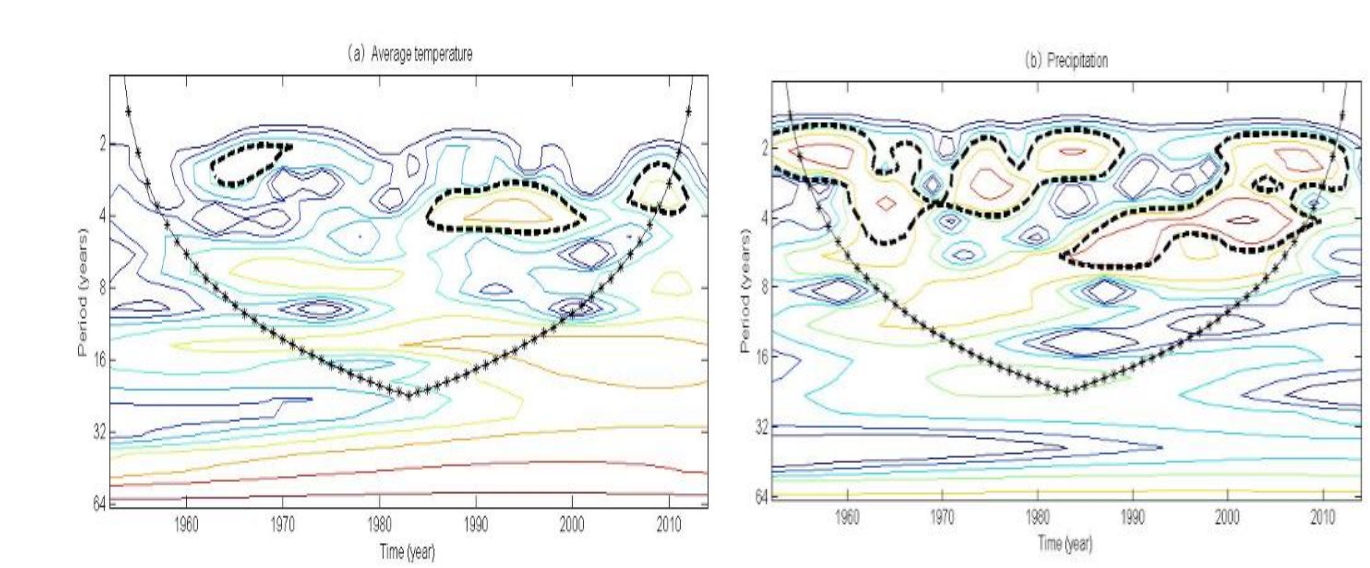

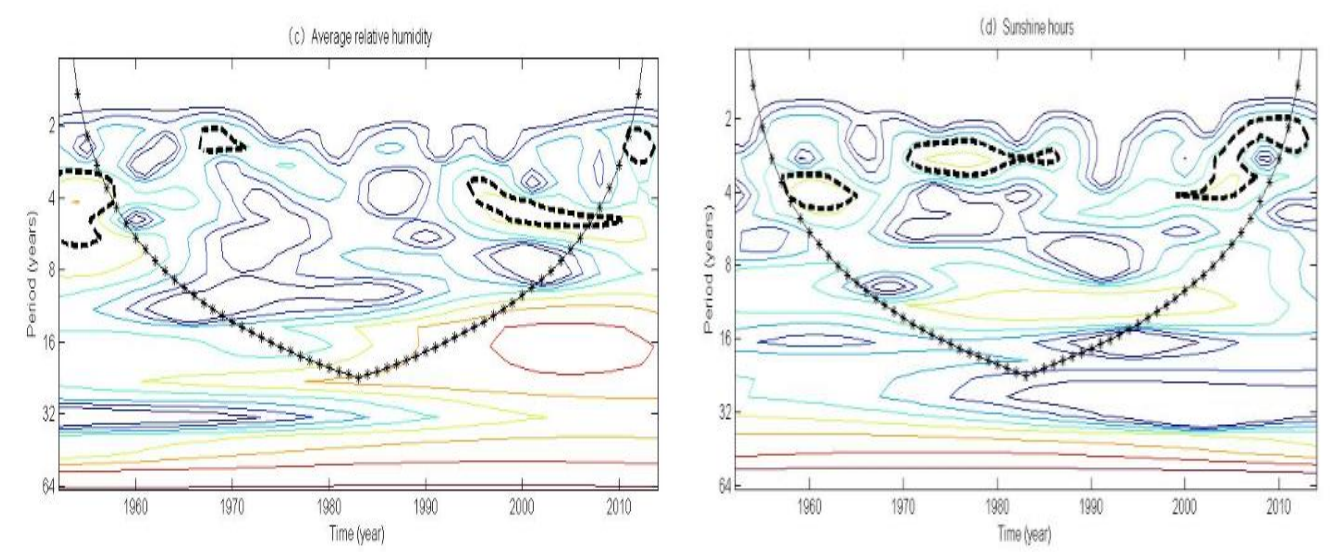

Figure 5. The Wavelet Power Spectrum Diagram of Climate Factors

\section{Analysis on the Mutation of Climate}

In this paper, we use the Mann-Kendall mutation test method to test the major factor in climate change trend in Guangzhou in the past 65 years, the results are shown in Figure 6.

\subsection{The Mutation Analysis to Temperature}

\subsubsection{The Average Minimum Temperature}

As can be seen from Figure 6 (a), there has been arsignificant increasing trend of the average minimum temperature in Guangzhou since the 1980s, and after 1991 this increasing trend is far more than a significant level 0.05 critical line (u0.05 $= \pm 1.96)$, which illustrate the upward trend is very significant, and it's consistent with the annual changes in the average minimum temperature before. According to the intersection curve position of UF and UB the mutation point of the average minimum temperature' increasing trend in Guangzhou is 1985, and the mutation point in the 0.05 confidence interval, which indicating that they have a higher credibility.

\subsubsection{The Average Maximum Temperature}

Figure 6 (b) shows that the average maximum temperature in Guangzhou in the state of strong fluctuations before the 1990s, it increased significantly after the nineties, and the warming trend is more obvious from 2000, which far more than the significance level of 0.05 critical line (u0.05 $= \pm 1.96$ ). It indicating that the increasing trend is very significant, this is consistent with the inter-annual changes in average maximum temperature analysis before. In addition, according to the curve intersection location of UF and $O B$, we can see the average maximum temperature increasing trend has mutant phenomenon in 1989, and the specific mutations began in 1990.

\subsection{The Annual Average Temperature}

As shown in Figure 6 (c), the average temperature shows a trend of decreasing, increasing, decreasing, and then increasing before 1985, after nineties it has a significant increasing trend. This trend were far more than the significance level of 0.05 critical line ( $u 0.05= \pm 1.96)$ since 1991. Combining with the mutation test and analysis of the average minimum temperature and the average maximum temperature, we can find that the average temperature is mainly affected by the average maximum temperature before 1985, while after 1985, the warming trend is affected by the changes of the average minimum temperature. According to the intersection location of UF and UB, we can determine the average temperature increasing trend after 1985 is a mutant phenomenon, 
and the mutation began in 1986 specifically, which were consistent with the mutations law of the average minimum temperature.

\subsection{The Precipitation}

As it shows in Figure 6 (d), the precipitation in Guangzhou fluctuated without obvious regularity before 1992. After 1992 the precipitation shows an increasing trend, but the magnitude of the rise is in a constant state of fluctuation. These increase trends doesn't exceed the significant level of 0.05 critical line, which indicating its significance is not obvious.

\subsection{The Average Relative Humidity}

As shown in Figure 6 (e), the average relative humidity in Guangzhou first decreases and then increases before 1988, it has a decreasing trend since 1988, and this decreasing trend presenting a higher significance after 2004 which has passed the significance test of 0.05 . According to the intersection position of UF and UB, it can be seen that the Cecrease tendency of the average relative humidity is a phenomenon of mutation and the mutation point is in 1995, which were in significance level of 0.05 the critical line (u0. $05= \pm$ 1.96).

\subsection{The Sunshine Hours}

As it can be seen from Figure 6 (f), the sunshine hours in Guangzhou has been significantly decreasing trend since 1965 , this decreasing trend far exceeds the significance level of 0.05 critical line $(\mathrm{u} 0.05= \pm 1.96)$ after 1973 , which is consistent with the interannual variability analysis of the sunshine bours before. According to the intersection position of the UF and UB, 1972 is the mutation point of the sunshine hours in Guangzhou.

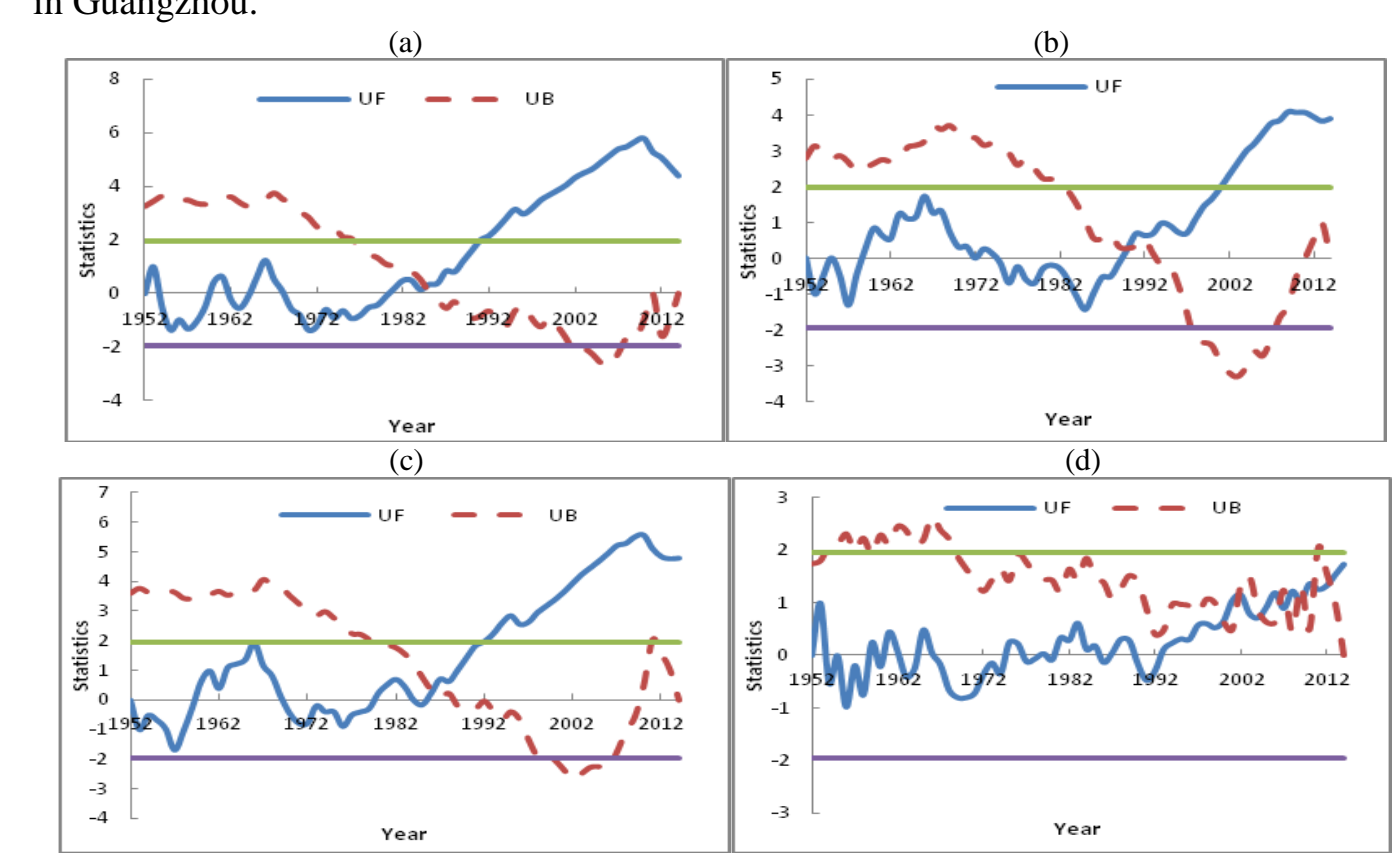

(e) 

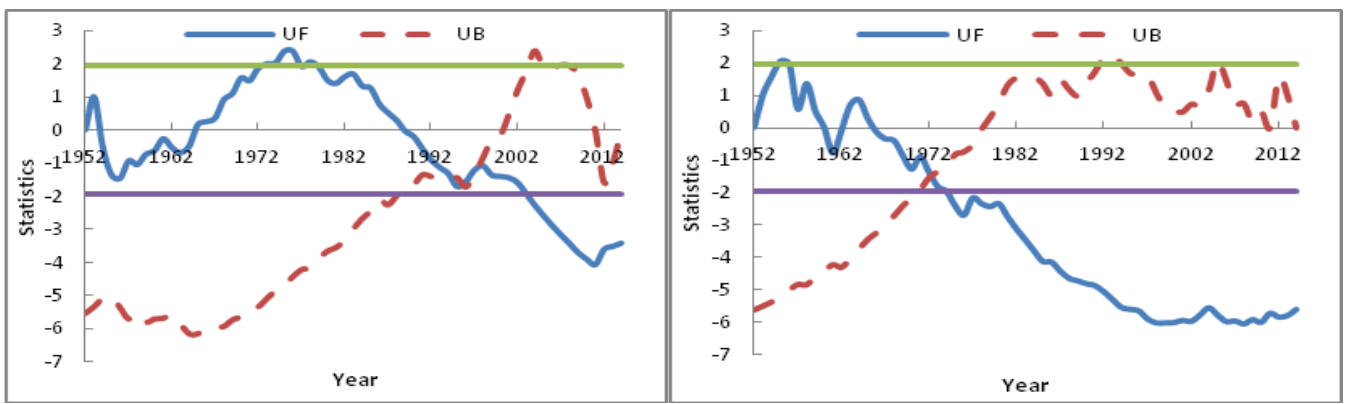

Note: The solid line is the confidence level of $95 \%$ of the critical line, numerical size is \pm 1.96

Figure 6. Mann-Kendall Statistic Curve of Climatic Factors: (a) The Average Minimum Temperature; (b) The Average Maximum Temperature; (c) The Average Temperature; (d) The Precipitation; (e) The Average Relative Humidity; (f) The Sunshine Hours

\section{Conclusions}

The average temperature in Guangzhou has an obvious increasing trend with the rate of $0.153{ }^{\circ} \mathrm{C} / 10 \mathrm{a}$ in nearly 65 years. According to the Mam-Kendall-mutation test, we can find that the average temperature is mainly affected by average maxinum temperature before 1985, while after 1985, it is mainly affected by the increase of average minimum temperature. Since the $50 \mathrm{~s}$ of last century, the increasing rate of the average minimum temperature is higher than the average maximum temperature in Guangzhou $\left(0.15{ }^{\circ} \mathrm{C} /\right.$ $10 \mathrm{a}>0.14{ }^{\circ} \mathrm{C} / 10 \mathrm{a}$ ), it also shows the change of the average temperature in Guangzhou is not "more and more hot", but "more andmore notcold CWhile it has a decreasing trend in recent years, the decreasing trend is more likely at the end effector of the 2005 - 2013 associate of $4 \mathrm{a}$ cycle by Morlet Wayelet transform analysis, there may be a increasing trend of temperature in the coming years.

The precipitation and humidity in Guangzhou show a decreasing trend. Affected by marine monsoon climate, El Niño and global warm and cold current, the precipitation has strong fluctuation in nearly 65 years. We can't find the significant rule by wavelet analysis and trend analysis. White the precipitation overall shows an increasing trend at the rate of $37.77 \mathrm{~mm} / 10 \mathrm{a}$, the average relative humidity has appeared a more significantly decreasing trend, which indicate that with the development of urbanization and the underlying surface changes in Guangzhou, the "dry island effect" in Guangzhou are more and more significant

The sunshine hour of Guangzhou have a significantly decreasing trend after 1965, and this trend reached the mutation point after 1973. The decreasing rate of sunshine hours is 88.6h / 10a throughout 65 years, with $3 \sim 4 a$ 's change cycle, this phenomenon may be related to the decline urbanization air quality. According to the research[7], the air quality of Guangzhou has improved significantly since the 21st, which is coincide with the increasing trend of the sunshine hours nearly a decade.

\section{Acknowledgments}

This paper is a revised and expanded version of a paper entitled "Analysis on Climate Change of Guangzhou in Nearly 65 Years" presented at ISI 2016, August 19-20, Harbin, China. This work is supported by the Dynamic mechanism of desertification in response to climate change in Qinghai Lake (41375160), evaluation of solar energy resources and the related studies of efficiency and effectiveness of photovoltaic (1213013) and effect of urbanization on climate change_—a case study of Yangtze River delta (2010JDXM027). Prof. Wenzheng $\mathrm{Yu}$ is the corresponding author. 


\section{References}

[1] J. Alcamo, G.J.J. Kreileman and M.S. Krol, "Modeling the global society -biosphere-climate system: Part I: Model description and testing", IMAGE 2.0: Integrated Modeling of Global Climate Change, Water, Air, and Soil Pollution, vol. 76, (1994), pp. 1-35.

[2] W.E. Hughes and R.C. Balling, "Urban influences on South African temperature trends", Int Climate, vol. 16, (1996), pp. 935-940.

[3] J.M. Shepherd, "Evidence of urban induced precipitation variability in arid climate regimes", Journal of Arid Environments, vol. 67, no. 4, (2006), pp. 607-628.

[4] J. Zhang and L. Zhou, "On the Effect of Urban Climate in Xining City", Journal of Xuzhou Normal University (Natural Science Edition), vol. 15, no. 4, (1997), pp. 47-51.

[5] S. C. Liu, C. Hb Wang and C. J. Shiu, "Reduction in sunshine duration over Taiwan: causes and implications", Terrestrial, Atmospheric and Oceanic Sciences, vol. 13, no. 4, (2002), pp. 523.545.

[6] Y. Wang, F. Yan and P. Zhang, "Study on Urban Heat Island Changes in Beijing Using Normalized Difference Vegetation Index and Albedo Data", Research of Environmental Sciences, vol. 22, no. 2, (2009), pp. 215-220.

[7] Q. Yu and H. Yang, "The Analysis of the Current Situation and the Variation Trend of Air Quality in" Guangzhou", Environmental Monitoring in China, vol. 26, no. 4, (2010), pp. 74-77.

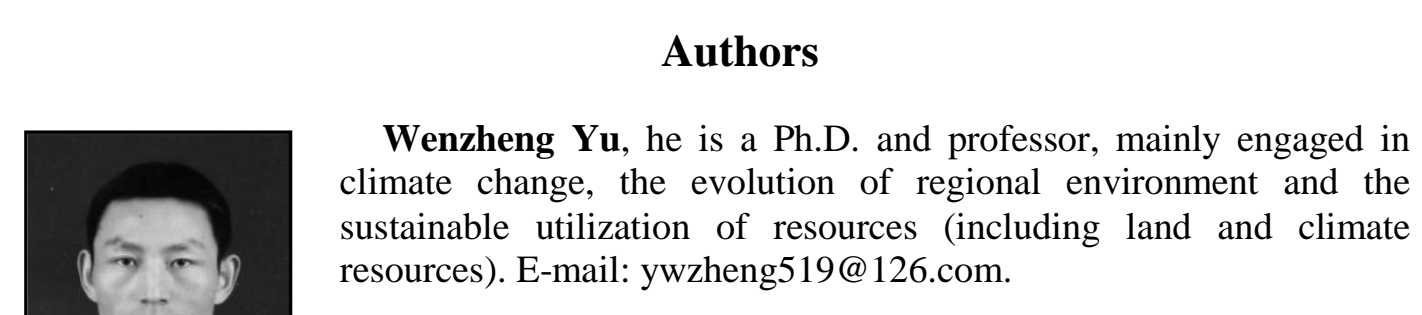
resources). E-mail: ywzheng519@126.com.

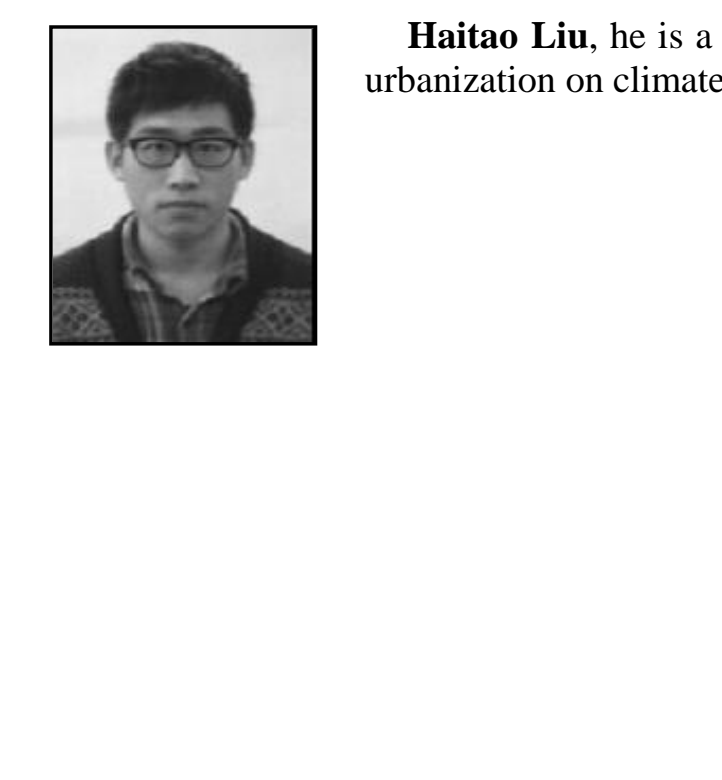

